\title{
Amino Acid Profiles and Compositions of Different Cultivars of Panicum miliaceum L.
}

\author{
Verena Wiedemair $^{1}\left[\right.$ - Sabine Scholl-Bürgi ${ }^{2} \cdot$ Daniela Karall $^{2} \cdot$ Christian W. Huck $^{1}[$
}

Received: 19 December 2019 / Revised: 16 April 2020 / Accepted: 27 April 2020 / Published online: 13 May 2020

(c) The Author(s) 2020

\begin{abstract}
Amino acids are valuable nutrients, responsible for a variety of tasks in the human body. A favourable amino acid profile in gluten-free crops, such as millet, can thus be beneficial for human health, which is why 35 proso millet (Panicum miliaceum L.) samples, comprising 23 whole and 12 dehulled, were investigated regarding their amino acid profiles and compositions using acidic hydrolysis and ion-exchange chromatography with ninhydrin derivatization and subsequent detection with photometry. Results for amino acid compositions were compared with gluten-containing wheat and other gluten-free cereals. Furthermore, gained values were put in contrast to estimated essential amino acid requirements for adult humans. The study was able to show that cultivars of proso millet differ and that dehulling does not significantly influence the amino acid compositions. Furthermore, the results display that Panicum miliaceum L. holds more essential amino acids than other gluten-free grains and exhibits high amounts of leucine and alanine. The methionine content differs greatly between samples, which means that choosing certain cultivars is important to ensure a high content. The most abundant amino acids in proso millet grains are glutamic acid/glutamine $(2.13 \pm 0.34 \mathrm{~g}$ per $100 \mathrm{~g})$, alanine $(1.06 \pm 0.18 \mathrm{~g}$ per $100 \mathrm{~g})$ and leucine $(1.36 \pm 0.24 \mathrm{~g}$ per $100 \mathrm{~g})$.
\end{abstract}

Keywords Ion-exchange chromatography $\cdot$ Proso millet $\cdot$ Amino acid composition $\cdot$ Nutrition $\cdot$ Cultivars

\section{Introduction}

Proso millet is an ancient crop and has been part of the human diet since the Neolithic times [1]. It is a gluten-free cereal, which is drought-resistant and can grow on soils

Electronic supplementary material The online version of this article (https://doi.org/10.1007/s10337-020-03899-8) contains supplementary material, which is available to authorized users.

Christian W. Huck

christian.w.huck@uibk.ac.at

Verena Wiedemair

verena.wiedemair@student.uibk.ac.at

Sabine Scholl-Bürgi

sabine.scholl-buergi@tirol-kliniken.at

Daniela Karall

Daniela.karall@tirol-kliniken.at

1 Institute of Analytical Chemistry and Radiochemistry, CCBCenter for Chemistry and Biomedicine, Leopold-Franzens University, Innrain 80-82, 6020 Innsbruck, Austria

2 Pädiatrie I, Medizinische Universität Innsbruck, Anichstraße 35, 6020 Innsbruck, Austria which are low in nutrients [2-4]. Millet may prove to be an alternative for coeliacs, people with non-coeliac gluten sensitivity (NCGS) and food style adapts [5]. Coeliac disease is a chronic auto-immune disorder, where inflammations in the small intestine occur through exposure to gluten. If patients consume gluten on a regular basis, severe ablation of the intestinal villi can be observed [6]. The prevalence of coeliac disease is about 1-3\% in Europe and the USA [7]. The disease is often diagnosed at a young age and the only cure is to follow a strict gluten-free diet for life [7, 8]. Lately, also people without health conditions try to reduce gluten in their diets or avoid it completely. This stems from the general notion that gluten-free food is healthier [9]. Reducing or avoiding gluten without the advice of a nutritionist or doctor can however lead to malnutrition due to a less balanced diet. A gluten-free diet often contains fewer carbohydrates and more salt and fat than recommended. Furthermore, gluten-free crops often have a lower protein content and less dietary fibre than gluten-containing cereals [10-16]. Nevertheless, gluten-free crops like proso millet can help to diversify diets and eat less wheat-based products. This is 
why the implementation of gluten-free and ancient crops in diets is encouraged.

Amino acids are an important class of nutrients. The human body uses them for protein synthesis, cell signalling, synthesis of low-molecular weight nitrogenous substances as well as substrates in certain metabolisms [17, 18]. Amino acids can be grouped into essential (EAA) and non-essential amino acids (N-EAA). The latter can be synthesised in the human body, whereas the former need to be added through diet. Threonine, valine, methionine, isoleucine, leucine, phenylalanine, histidine and lysine belong to the group of essential amino acids, whereas aspartic acid, asparagine, serine, glutamic acid, glutamine, proline, glycine, alanine, tyrosine and arginine belong to the group of non-essential amino acids. Histidine is actually a semi-essential amino acid, which means that it is partially synthesised in the human body. In the interest of simplicity, it is grouped with the essential amino acids in this work.

This study deals with the amino acid profiles and compositions of different cultivars of Panicum miliaceum $\mathrm{L}$. (namely cv. AUT-, cv. AUT-2, cv. Early Bird, cv. Gierczyckie, cv. GLRH16106, cv. Horizon, cv. Huntsman, cv. ITA4, ITA-5, cv. Jagna, cv. Kornberger, cv. Lisa, cv. Quartett, $\mathrm{cv}$. Sunrise and cv. Tiroler) and investigates the variation between them. All grains were sown and harvested in Austria and Italy. Whole and dehulled grains were also examined regarding their differences. The latter were produced using a conventional dehuller (Yamomoto, FC2K-Y, Yamagata, Japan) before analysis. Proso millet grains are often dehulled before food processing to reduce storage volume and improve sensory and edible quality [19]. Proso millet flours, however, can be purchased from whole or dehulled grains, consequently both types need to be investigated. By understanding the possible differences between cultivars and the effect of dehulling on the grains, it will be possible to identify favourable samples for food consumption and breeding.

\section{Methods and Materials}

\section{Sample Management}

A set of 35 proso millet (Panicum miliaceum L.) grains whole and dehulled were analysed for their amino acid profile. All samples were dried whole in an infrared chamber at $35^{\circ} \mathrm{C}$ for three days after harvest. Then, some samples were divided into two parts and one part was dehulled, while the other was not. For dehulling a conventional dehuller was used to remove the hull before analysis. All samples whole and dehulled were stored in a freezer at $-20^{\circ} \mathrm{C}$ until analysis. The final moisture content was $9.4 \pm 0.4 \mathrm{~g}$ per $100 \mathrm{~g}$ for all samples after thawing and was analysed using a standard method [20].

Since the husk of proso millets is often removed before food processing, the set included 23 whole and 12 dehulled samples. Furthermore, the sample set comprised 15 unique cultivars, but some samples were sowed and harvested in two consecutive years. All cultivars were harvested from trial fields in Austria and Italy. Supplementary Table 1 shows the acronyms of the samples and their year of harvest.

\section{Chemicals}

For the hydrolysis of the samples $6 \mathrm{~mol} \mathrm{~L}^{-1}$ hydrochloric acid, which was produced by mixing fuming $\mathrm{HCl}$ (11.6 mol L ${ }^{-1}$, Carl Roth, Karlsruhe, Germany) with deionized water which passed a reverse osmose system twice $(18.2 \mathrm{M} \Omega \mathrm{cm})$, was used. The samples were then mixed with Lithium Citrate Loading buffer $(\mathrm{pH}=2.2)$, internal standard (S-2-aminoethyl-L-cystein-hydrochloride, $\left.2.5 \mu \mathrm{mol} \mathrm{L}^{-1}\right)$, $50 \mathrm{~g}$ per $100 \mathrm{~mL}$ sulfosalicylic acid and $1 \mathrm{~mol} \mathrm{~L}^{-1}$ sodium hydroxide. The amino acid analyser used five different Lithium Citrate buffers between $\mathrm{pH} 2.8$ and 3.55 as a mobile phase. Furthermore, a Lithium Regeneration buffer with $\mathrm{pH}$ over 13 was used to regenerate the column after each run. All lithium-containing buffers and ninhydrin were purchased from Biochrom (Berlin, Germany). The external standard calibration was measured using the physiological standard mix from Laborservice Onken (Gründau, Germany), which contains 42 different amino acids and their derivatives, each with a concentration of $1 \mu \mathrm{mol} \mathrm{mL}-1$.

\section{Determination of Amino Acid Profile}

\section{Sample Preparation}

To investigate amino acids, all proteins in the samples have first to be split into their building amino acids. Thus, all samples were first subjected to acid hydrolysis according to an international standard method $[21,22]$. Therefore, $50 \mathrm{~mL}$ of $6 \mathrm{~mol} \mathrm{~L}^{-1}$ hydrochloric acid were added to $0.5 \mathrm{~g}$ of ground samples and stirred under reflux for $24 \mathrm{~h}$ at $110^{\circ} \mathrm{C}$ without purging out air. Afterwards, the hydrolysates were filtered through a fritted glass with a porosity of 4 to remove solid particles and then hydrochloric acid was removed by using a rotary evaporator (Büchi, Flawil, Switzerland). The hydrolysate was evaporated at $60^{\circ} \mathrm{C}$ and 40 bar until an oily residue, which could not further be evaporated, was yielded. The residue was washed three times using $20 \mathrm{~mL}$ of deionized water. Lastly, $25 \mathrm{~mL}$ of deionized water from a MilliQ device (18.2 M $\Omega \mathrm{cm}$ ) (Merck, Darmstadt, Germany) were added to the residue.

Next, the samples were filtered again using a $0.2 \mu \mathrm{m}$ sterile non-pyrogenic filter with a polyethersulfone (PES) 
membrane. Then, $500 \mu \mathrm{L}$ of samples were diluted with 1000 $\mu \mathrm{L}$ Lithium Citrate Loading buffer ( $\mathrm{pH}$ 2.2). Next, $500 \mu \mathrm{L}$ of this solution were mixed with $50 \mu \mathrm{L}$ of internal standard and $50 \mu \mathrm{L} 50 \%$ sulfosalicylic acid. The mixture was vortexed and then centrifuged at $10,700 \mathrm{rpm}(10,880 \mathrm{~g})$ for $5 \mathrm{~min} .300 \mu \mathrm{L}$ of the supernatant were mixed with $300 \mu \mathrm{L}$ of Lithium Citrate Loading buffer and finally $30 \mu \mathrm{L}$ of $1 \mathrm{~mol} \mathrm{~L}^{-1}$ sodium hydroxide solution were added. The mix was then stored at $-20{ }^{\circ} \mathrm{C}$ until analysis. Each sample was prepared for analysis three times.

\section{Analysis of Amino Acid Composition with Icon-Exchange Chromatography}

The amino acid profile was determined using an amino acid analyser (Biochrom 30+, Biochrom, Cambridge, UK), which is based on ion-exchange chromatography [23]. It was calibrated using an external standard and a response factor. Furthermore, an internal standard was used to control the separation and the derivatisation. The Biochrom $30+$ separated the amino acids using a high-pressure PEEK column packed with Ultropac 8 cation exchange resin. The mobile phase comprised buffers of varying $\mathrm{pH}$. After column separation, the eluent was mixed with a ninhydrin reagent at $135^{\circ} \mathrm{C}$ and passed through a high-temperature reaction compartment with $10 \mathrm{~m}$ length and $0.3 \mathrm{~mm}$ diameter with $20 \mathrm{~mL} \mathrm{~h}^{-1}$. Ninhydrin reacted with the amino acids and yielded a coloured complex, which was used for detection with a photometer. The absorbance was measured at two wavelengths: 570 and $440 \mathrm{~nm}$. The column was then cleaned and regenerated using the Lithium Citrate Regeneration buffer and the Lithium Citrate Loading buffer [24]. The concentrations of the amino acids were then calculated using external standards and their respective response factors.

For sample measurements, the temperature was adjusted during the run. In the first $36 \mathrm{~min}$ the column was heated to $30{ }^{\circ} \mathrm{C}$, then the temperature was changed to $43{ }^{\circ} \mathrm{C}$ for $15 \mathrm{~min}$ followed by a change to $50{ }^{\circ} \mathrm{C}$ for $3.5 \mathrm{~min}$. Next, the temperature was set to $70{ }^{\circ} \mathrm{C}$ for $21 \mathrm{~min}$ and then to $76{ }^{\circ} \mathrm{C}$ for $46 \mathrm{~min}$. After that, the column was cooled to $70{ }^{\circ} \mathrm{C}$ for $20 \mathrm{~min}$ and finally the column was cooled to $33^{\circ} \mathrm{C}$ for $14 \mathrm{~min}$. The flow rate was kept constant at $25.0 \mathrm{~mL} \mathrm{~h}^{-1}$. The mobile phase followed a $\mathrm{pH}$-gradient, which was created by lithium citrate buffers with varying $\mathrm{pH}$ values. For the first 6 min, a buffer with $\mathrm{pH} 2.8$ was used, followed by a Lithium Citrate buffer with $\mathrm{pH} 3.0$ for $30 \mathrm{~min}$. Next, the mobile phase was changed to a buffer with $\mathrm{pH} 3.15$ for $18.5 \mathrm{~min}$ and then to a buffer with $\mathrm{pH} 3.5$ for $21 \mathrm{~min}$. Then, a mobile phase with $\mathrm{pH} 3.55$ was used for $32 \mathrm{~min}$ followed by the Lithium Citrate Regeneration buffer with $\mathrm{pH}>13$, which was used for 6 min. For the remaining run time, the first buffer with pH 2.8 was used. In total the run time was $119.5 \mathrm{~min}$.

\section{Data Evaluation}

For statistical evaluation of the measured amino acid concentrations, the means and standard deviations were calculated. Additionally, the medians of hulled and dehulled samples were calculated, to compare them to their respective means. Statistical differences between hulled and dehulled samples from the 1st and 2 nd year of harvest were evaluated using one-way ANOVA $(\alpha=0.05)$. The correlation between each individual amino acid concentration and the sum of amino acid concentrations was determined using the Pearson correlation coefficient.

\section{Results and Discussion}

\section{Amino Acid Profiles}

The amino acid concentrations were calculated using an external standards and their respective response factors and are given in $\mathrm{g}$ per $100 \mathrm{~g}$ sample. In this study aspartic acid/asparagine, threonine, serine, glutamic acid/glutamine, glycine, alanine, valine, methionine, isoleucine, leucine, tyrosine, phenylalanine, lysine, histidine, arginine and proline were investigated. The proline content was determined at $440 \mathrm{~nm}$, all other amino acids were investigated at $570 \mathrm{~nm}$. Additionally, the sum of these amino acids was calculated, to get an idea about the total amount of amino acids in the samples. The crude protein content of all but two samples (15-Jagna-H and 19-Kornberger-H) was measured as well and already published in a previous study [25]. The association between the sum of amino acids and crude protein of the remaining samples was 0.92 according to the Pearson correlation coefficient. In Fig. 1 the sum of amino acid concentrations is listed for each sample.

The samples set holds dehulled and hulled samples. The sum of amino acid concentrations of all samples ranges from 6.91 to $14.30 \mathrm{~g}$ per $100 \mathrm{~g}$ and has a mean of $10.42 \mathrm{~g}$ per $100 \mathrm{~g}$ and a median of $10.19 \mathrm{~g}$ per $100 \mathrm{~g}$. The standard deviation (SD) of the total amino acid concentrations of all samples is $1.68 \mathrm{~g}$ per $100 \mathrm{~g}$ and the relative standard deviation (RSD) is $6.22 \%$. Hulled grains range from 6.91 to $14.30 \mathrm{~g}$ per $100 \mathrm{~g}$ with a mean of 10.59 and a median of $10.36 \mathrm{~g}$ per $100 \mathrm{~g}$. SD of samples with husk was $1.89 \mathrm{~g}$ per $100 \mathrm{~g}$ and RSD was 5.62\%. Dehulled samples had a sum of amino acid concentrations between 7.74 and $11.49 \mathrm{~g}$ per $100 \mathrm{~g}$ with a mean of 10.10 and a median of $10.14 \mathrm{~g}$ per $100 \mathrm{~g}$. SD of dehulled grains was $1.19 \mathrm{~g}$ per $100 \mathrm{~g}$ and RSD was $8.52 \%$.

Whole samples show a broader concentration range regarding the sum of amino acids (6.91-14.30 g per $100 \mathrm{~g})$ than dehulled samples $(7.74-11.49 \mathrm{~g}$ per $100 \mathrm{~g})$. 
Furthermore, the median of dehulled samples is closer to the respective mean compared to the median and mean of hulled samples. The lowest sum of amino acids was found in ITA-5 with husk, the highest in Kornberger with husk. The latter held about double the amount of amino acids than the former. ITA-5 without husk had the lowest amount of amino acids within the dehulled samples. The highest amount of amino acids in dehulled samples was found in ITA-4. Dehulled ITA- 5 holds about 1.5 times less amino acids than ITA-4 without husk. Comparing whole and dehulled samples using one-way ANOVA, a $p$ value of 0.42 was found, indicating no significant difference between the means of those two groups. Consequently, it can be postulated that there are hardly any amino acids in the husk. However, looking at each year individually, it is interesting to note that for the second year dehulled sample hold more amino acids, but in the first year the amounts are often quite similar or the dehulled samples have a smaller total sum of amino acids. For the cultivars Early Bird, GLRH16106, Quartett and Sunrise, the differences between samples whole and dehulled are not very pronounced. For some other cultivars, this difference is however very pronounced. Furthermore, the samples from the first year on average exhibit a higher amount of amino acids than samples from the second year. The respective $p$ value yielded with one-way ANOVA was below 0.05 , which means that the two years differ significantly from each other.

Of the investigated amino acids eight belong to the group of essential amino acids (phenylalanine, leucine, methionine, lysine, isoleucine, valine, threonine and histidine) for humans. The remaining eight are non-essential amino acids (glutamic acid/glutamine, glycine, alanine, aspartic acid/ asparagine, arginine, proline, serine and tyrosine). Tryptophan could not be measured since acid hydrolysis was performed and this amino acid can only be analysed using basic hydrolysis. Cysteine could also not be analysed as it is not stable during acid hydrolysis [26]. Additionally, the amino acids can be group into basic amino acids (lysine, arginine and histidine), polar amino acids (tyrosine, threonine, glycine, serine, aspartic acid/asparagine and glutamic acid/glutamine) and nonpolar amino acids (methionine, alanine, valine, leucine, isoleucine, proline and phenylalanine) In Fig. 2 a box plot with error bars depicts the distribution of the different amino acids in the samples.

It becomes clear that the most abundant amino acids are glutamic acid/glutamine and leucine, whereas the least abundant are methionine and lysine. Additionally, more abundant amino acids differ more between samples than less abundant amino acids - the only exception being methionine. The three basic amino acids investigated show a low abundance. Looking at polar amino acids, only glutamic acid/glutamine is highly abundant. All remaining polar amino acids are in the mid-abundance range relative to the other amino acids.
The non-polar amino acids vary from high to low abundance in the samples. Leucine and alanine are highly abundant in the samples, but methionine is not.

The results were in good agreement with previous studies [27-29] and other literature [30]. Furthermore, the results were compared to amino acid compositions found in the literature for wheat, rice and maize because those are the three most commonly used crops [31, 32]. Rice and maize are both gluten-free crops whereas wheat is the most commonly consumed gluten-containing crop in the world. Table 1 lists the amino acid compositions of wheat, maize, rice and proso millet.

Regarding the sum of the essential amino acids, proso millet contains approximately the same amount as wheat. Additionally, proso millet comprises in total significantly more essential amino acids than rice and maize. Furthermore, proso millet has the highest sum of N-EAA of the listed gluten-free crops. Only wheat holds more N-EAA, which is mostly due to the high amount of glutamic acid/ glutamine in wheat. Proso millet also has the highest total sum of amino acids of the listed gluten-free grains.

The limiting essential amino acid for wheat and maize is methionine. For proso millet lysine and methionine are limiting essential amino acids and for rice histidine and methionine are limiting. Table 1 shows that proso millet holds more threonine, leucine, serine, alanine and tyrosine than the three most commonly used crops. However, proso millet also holds the lowest amounts of lysine and glycine. For most amino acids, wheat exhibits the highest abundances and rice the lowest.

In the next step, it was investigated whether or not certain cultivars exhibit exceptionally high or low amounts of certain amino acids. These cultivars would then be suitable for food processing, as well as good choices for breeding new proso millet cultivars. Figure 3 depicts the relative abundance of all amino acids in all samples. The results were obtained by calculating the mean of each amino acid and setting it as 1 and then expressing the abundance of each amino acid of each sample as a multiple of the mean.

The most average sample is probably $30-$ Sunrise-H. All amino acids except for threonine and methionine are close to the respective means. It is also apparent that methionine has the largest variance among the samples. Furthermore, Fig. 3 shows that if a sample has a high amount of amino acids this is not attributed to just one amino acid, but to all amino acid levels being elevated. The only exception is methionine, as it is not correlated with the rise or decline of the remaining amino acids. This is also confirmed in Table 2, where the Pearson correlation coefficient between amino acids and sum of amino acids is listed.

Methionine correlation to the total amount of amino acids is close to zero. Threonine and lysine also have a very low correlation to the overall amount of amino acids 


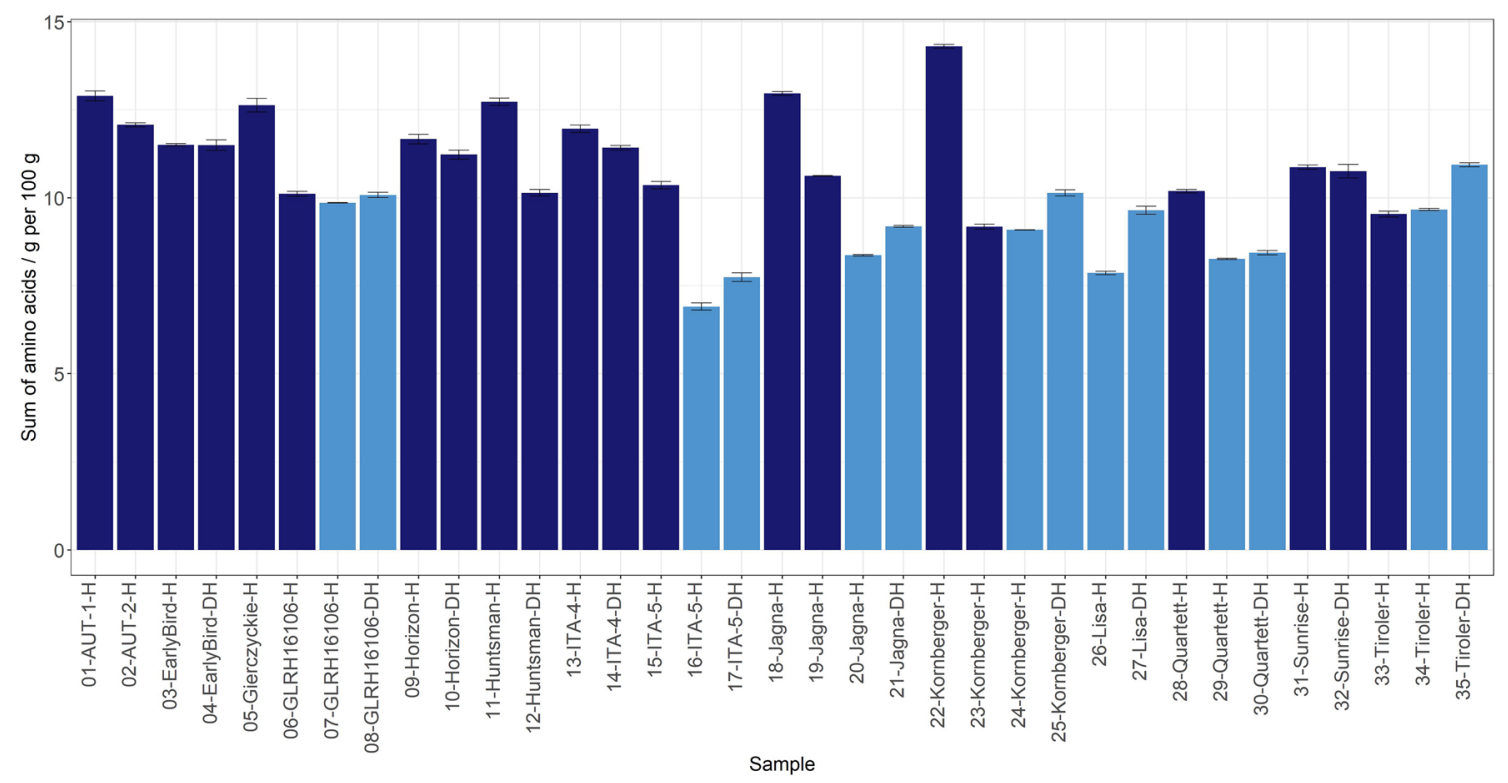

Fig. 1 Sum of amino acids for each sample. Dark blue —2016, year of harvest; light blue—2017, year of harvest. $H$ whole samples, $D H$ dehulled samples

in the sample. In Fig. 2 it is evident that lysine concentration is approximately the same for all the samples, which explains the low correlation to the total amino acid concentration. Additionally, glycine and arginine have a correlation value of about 0.9 . Both amino acids have a rather low abundance in proso millet samples and also have a low variance across samples.

\section{Nutritional Implications}

In Europe wheat and corn dominate the crop market, but recently proso millet and other gluten-free grains gained popularity. Table 1 clearly shows that proso millet holds more amino acids than other gluten-free crops. Table 3 below shows the estimated essential amino acid requirements of human adults [34] in comparison to the found amino acid concentrations in the samples. Phenylalanine and tyrosine as well as methionine and cysteine are listed as one parameter because cysteine and tyrosine can partly replace methionine and phenylalanine in the human body [34, 35].

The two most abundant essential amino acids in the investigated proso millet samples and the two most highly required EAA are leucine and phenylalanine/tyrosine. Lysine, histidine and methionine/cysteine are also required in the human diet, however, the former three EAA are not highly abundant in the investigated proso millet samples. The content of cysteine was not measured in this study. Consequently, a diet which integrates proso millet should be complemented with other lysine-, histidine- and methioninerich foods. By choosing specific cultivars of proso millet, the methionine intake can also be influenced.

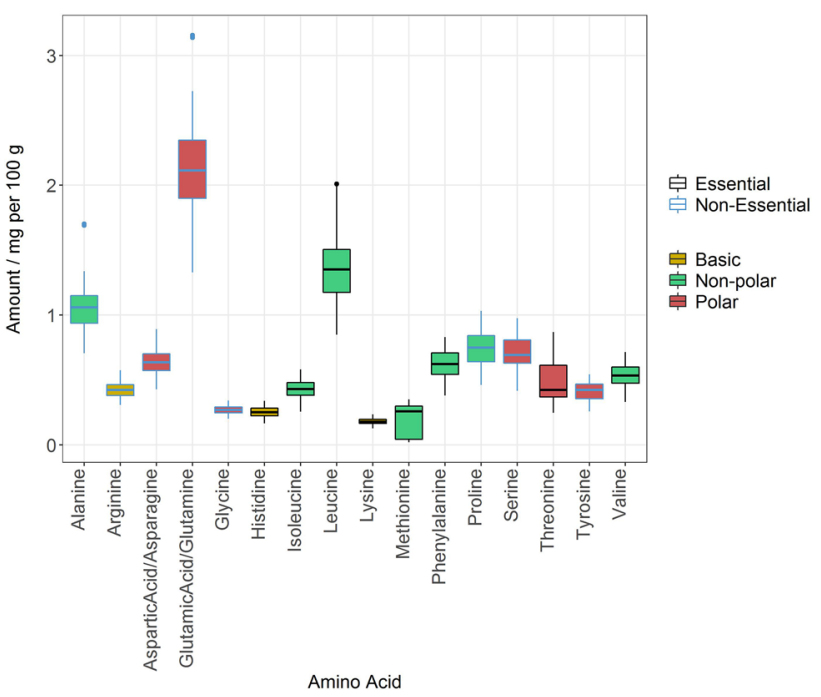

Fig. 2 Box plot with error bars of the distribution of each amino acid in all samples. The bold line in the box indicates the median and the box refers to the 2 nd and 3rd quartile. The 1 st and 4th quartiles are indicated by the lines below and above each box

Additionally, asparagine can be transformed into acrylamide when sugar is present during food processing [36]. Hence, a low asparagine content is beneficial for health and lowers the risk of acrylamide formation. In general, proso millet has a low aspartic acid/asparagine concentration. 
Table 1 Comparison of amino acid compositions of durum wheat, maize, medium-grain unenriched white rice and proso millet

\begin{tabular}{llcllc}
\hline Essential/non-essential & Amino acid & $\begin{array}{l}\text { Wheat } / g \\
\text { per } 100 \mathrm{~g}\end{array}$ & $\begin{array}{l}\text { Maize } / g \\
\text { per } 100 \mathrm{~g}\end{array}$ & $\begin{array}{l}\text { Rice }^{\mathrm{a}} / \mathrm{g} \text { per } \\
100 \mathrm{~g}\end{array}$ & $\begin{array}{l}\text { Millet } / g \\
\text { per 100 g }\end{array}$ \\
\hline EAA & Threonine & 0.37 & 0.35 & 0.24 & 0.49 \\
& Valine & 0.59 & 0.48 & 0.40 & 0.54 \\
& Methionine & 0.22 & 0.20 & 0.16 & 0.18 \\
& Isoleucine & 0.53 & 0.34 & 0.29 & 0.43 \\
& Leucine & 0.93 & 1.16 & 0.55 & 1.35 \\
& Phenylalanine & 0.68 & 0.46 & 0.35 & 0.63 \\
N-EAA & Histidine & 0.32 & 0.29 & 0.16 & 0.25 \\
& Lysine & 0.30 & 0.27 & 0.24 & 0.18 \\
& Aspartic acid/asparagine & 0.62 & 0.66 & 0.62 & 0.64 \\
& Serine & 0.67 & 0.45 & 0.35 & 0.71 \\
& Glutamic acid/glutamine & 4.74 & 1.77 & 1.29 & 2.12 \\
& Proline & 1.46 & 0.82 & 0.31 & 0.75 \\
Sum N-EAA & Glycine & 0.50 & 0.39 & 0.30 & 0.27 \\
& Alanine & 0.43 & 0.71 & 0.38 & 1.06 \\
& Tyrosine & 0.36 & 0.38 & 0.22 & 0.42 \\
& Arginine & 0.48 & 0.47 & 0.55 & 0.42 \\
& & 3.94 & 3.55 & 2.39 & 4.05 \\
& & 9.26 & 5.65 & 4.02 & 6.39 \\
& & 13.20 & 9.20 & 6.41 & 10.44 \\
\hline
\end{tabular}

$E A A$ essential amino acids, $N$-EAA non-essential amino acids

a Data was taken from the National Nutrient Database for Standard Reference from USDA [33]

${ }^{\mathrm{b}}$ Averages of measured data

\section{Reliability of Analysis}

Proso millets, just like other cereals, are dependent on the nutrients from the soil it grows on. Hence, the soil greatly influences nutritive properties of the harvested grains. To combat this, some samples were harvested in two consecutive years, to investigate if the amino acid profiles change from one year to another. Samples were grown in the same fields with the same soil in both years. The fields were located in Italy and Austria and had varying growing conditions. Some fields were located close to the sea, others in the Alps. Some fields were in a valley, others on a hillside. This way, a realistic experimental set-up was ensured, as on the European market proso millet is always only available as a mixture from a variety of fields. As already mentioned in Sect. 3.1, the samples harvested in the first year have a slightly higher amount of amino acids than the samples from the second year. However, this is not due to an increase of a specific amino acid but related to an overall increase of amino acid concentrations. Consequently, the soil influenced the amount of total amino acids (see Fig. 1), but did not change the profile (see Fig. 3). This indicates that the overall growing conditions were better in the second year, which promoted higher amino acid abundances.
Hydrolysing proteins and measuring the amino acid profile afterwards is very precise, but has a few drawbacks. First of all, some amino acids are unstable during hydrolysis. Asparagine and glutamine are de-aminated and transformed to aspartic and glutamic acid. This was also the case in this study, but since the deamination affects these amino acids fully, the glutamic acid and aspartic acid peaks are used to determine the respective concentrations [37]. Serine and threonine are partially destroyed during hydrolysis, which is accounted for by internal standards and multiplication with a factor. Methionine is sometimes oxidized during hydrolysis. This is why derivatives of those amino acids are usually also monitored during analysis [37]. Furthermore, ion exchange chromatography is not able to distinguish between L- and D-amino acids. Consequently, the chirality is not specified. Additionally, the reaction with ninhydrin is often not complete. This does not pose a problem, as long as the ratio of derivatized amino acids is always the same [37].

Lastly, the measurements can vary from run to run and from day to day. This is why an interday and an intraday assay was used to determine the accuracy of the analysis (see supplementary Table 2). Five standards, comprising all amino acids investigated at a concentration of $2.5 \mu \mathrm{mol} \mathrm{mL}$ 


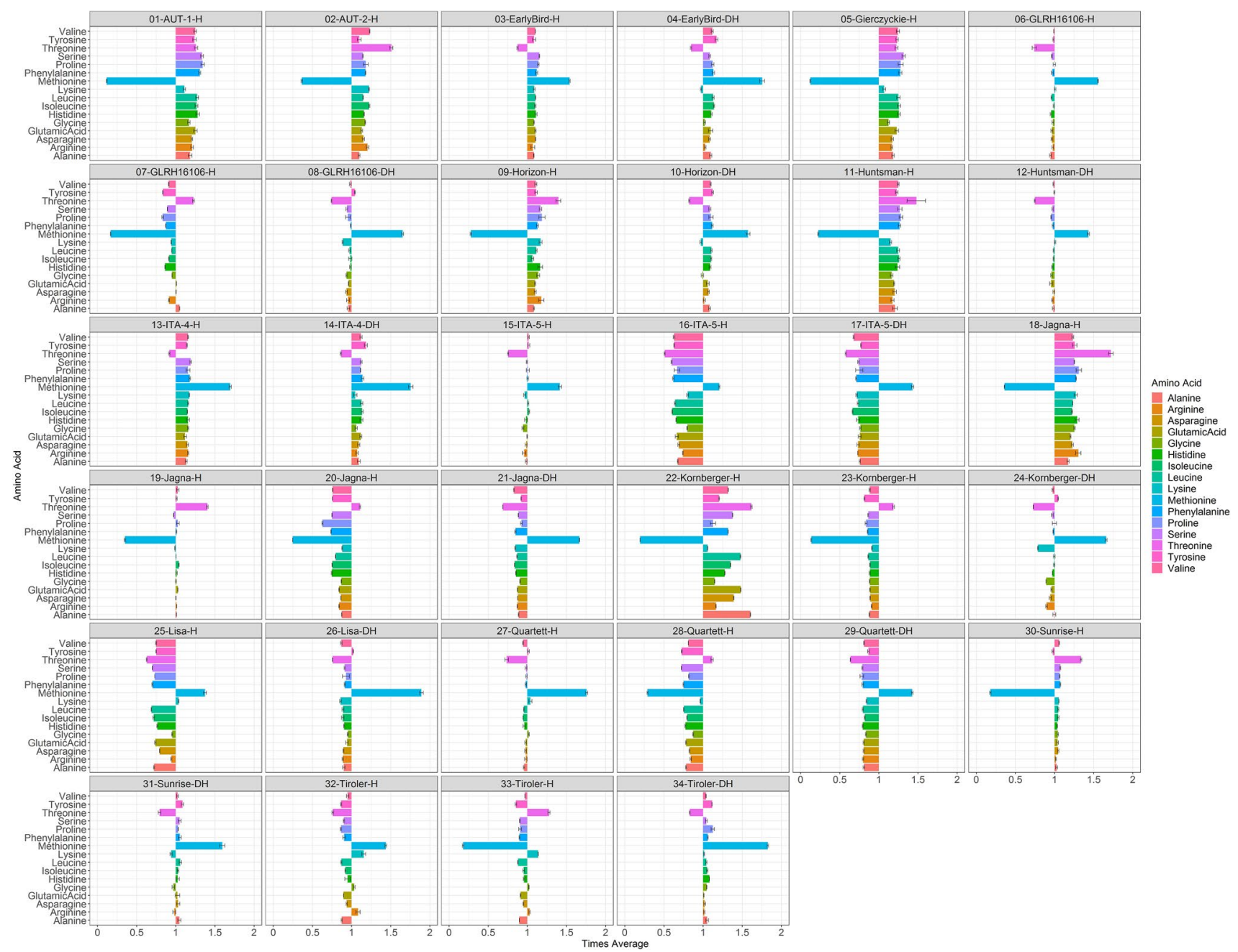

Fig. 3 Relative abundances of each amino acid in each sample, expressed as multiples of the mean, which is set as 1

in acidified water, were analysed for the inter- and for the intraday assay.

\section{Conclusion}

This study investigates 35 proso millet (Panicum miliaceum L.) samples regarding their amino acid profiles and compositions using ion-exchange chromatography. The results showed that although the amino acid profile is quite similar for all cultivars examined in this study, the concentrations vary greatly. Consequently, to assess the suitability of different types of millet (e.g. proso, pearl, finger millet) for consumption a variety of cultivars of each type need to be tested, as they already vary greatly in their nutritional parameters.

The obtained results were also compared to values for gluten containing and gluten-free grains. This revealed that proso millet holds the highest concentration of essential amino acids and thus is a valid alternative to durum wheat, maize or white rice. The amino acid profiles of proso millet were put in contrast to the estimated requirements of essential amino acids for adult humans. The results show that proso millet has high concentrations of phenylalanine/ tyrosine and leucine, which matches the high requirement of humans for these amino acid. Additionally, the methionine intake from proso millet can be regulated by choosing cultivars with high or low concentrations of this amino acid.

Lastly, this study highlights the statistical evaluation of the influence of different harvest years and pre-processing steps such as dehulling on the amino acid profiles and concentrations. Dehulled samples did not differ significantly from the whole samples. The year of harvest on the other hand, had a significant impact on the sum of amino acids in the samples. 
Table 2 Pearson correlation coefficient between the total amino acid and a specific amino acid

\begin{tabular}{lc}
\hline & $\begin{array}{c}\text { Pearson correlation } \\
\text { coefficient }\end{array}$ \\
\hline TAA-alanine & 0.955 \\
Taa-arginine & 0.900 \\
Taa-aspartic acid/asparagine & 0.990 \\
TAA-glutamic acid/glutamine & 0.985 \\
TAA-glycine & 0.899 \\
TAA-histidine & 0.983 \\
TAA-isoleucine & 0.986 \\
TAA-leucine & 0.993 \\
TAA-lysine & 0.681 \\
TAA-methionine & 0.224 \\
TAA-phenylalanine & 0.989 \\
TAA-proline & 0.932 \\
TAA-serine & 0.989 \\
TAA-threonine & 0.622 \\
TAA-tyrosine & 0.935 \\
TAA-valine & 0.985 \\
\hline
\end{tabular}

$T A A$ total amino acids

Table 3 Comparison between the estimated essential amino acid requirements of a human adult [34] and the found amino acid concentration in the proso millet samples

\begin{tabular}{lll}
\hline Amino acid & $\begin{array}{l}\text { Millet/g per } \\
100 \mathrm{~g}\end{array}$ & $\begin{array}{l}\text { Estimated requirement/ } \\
\mathrm{mg} \text { per kg body weight }\end{array}$ \\
\hline EAA & & \\
Threonine & 0.49 & 7 \\
Valine & 0.54 & 10 \\
Methionine and cysteine & 0.18 & 13 \\
Isoleucine & 0.43 & 10 \\
Leucine & 1.35 & 14 \\
Phenylalanine and tyrosine & 1.04 & 14 \\
Histidine & 0.25 & $8-12$ \\
Lysine & 0.18 & 12 \\
\hline
\end{tabular}

Acknowledgements Open access funding provided by University of Innsbruck and Medical University of Innsbruck. The authors want to thank the European Union, the European Regional Development Fund and the cross-border programme Interreg V-A Italy-Austria 2014-2020 (project "RE-Cereal", ITAT 1005, P-7250-013-042) for financial support. For sample management we want to thank Dr. Schär AG/SPA (Burgstall, Italy) and Research Centre Laimburg (Bolzano, Italy). The authors also want to extend their gratitude to Ulrike Eichinger-Öttel, Claudia Ertl and Christine Kluckner for sample analysis and their kind advice and support.

Author Contributions Conceptualization: VW, SS-B, DK, CH; methodology: VW, SS-B; formal analysis an investigation: VW; writingoriginal draft preparation: VW; writing-review and editing: VW,
SS-B, DK, CH; funding acquisition: VW, SS-B, DK, CH; resources: SS-B, D, CH; supervision: SS-B, CH.

Funding The research was funded by the European Union, the European Regional Development Fund and the cross-border programme Interreg V-A Italy-Austria 2014-2020 (project "RE-Cereal", ITAT 1005, P-7250-013-042).

Availability of data and material The data is available upon request. The sample material will be available until 06/2021.

\section{Compliance with Ethical Standards}

Conflicts of interest The authors declare no conflicts of interest.

Ethical approval The research involved no ethical issues concerning living beings. The authors complied with the ethical standards in publishing.

Open Access This article is licensed under a Creative Commons Attribution 4.0 International License, which permits use, sharing, adaptation, distribution and reproduction in any medium or format, as long as you give appropriate credit to the original author(s) and the source, provide a link to the Creative Commons licence, and indicate if changes were made. The images or other third party material in this article are included in the article's Creative Commons licence, unless indicated otherwise in a credit line to the material. If material is not included in the article's Creative Commons licence and your intended use is not permitted by statutory regulation or exceeds the permitted use, you will need to obtain permission directly from the copyright holder. To view a copy of this licence, visit http://creativecommons.org/licenses/by/4.0/.

\section{References}

1. Lu H, Zhang J, Liu K-B et al (2009) Earliest domestication of common millet (Panicum miliaceum) in East Asia extended to 10,000 years ago. Proc Natl Acad Sci USA 106(18):7367-7372. https://doi.org/10.1073/pnas.0900158106

2. Kumar A, Tomer V, Kaur A et al (2018) Millets: a solution to agrarian and nutritional challenges. Agric Food Secur 7(1):166. https://doi.org/10.1186/s40066-018-0183-3

3. Singh E, Sarita A (2016) Nutraceutical and food processing properties of millets: a review. J Nutr Food Sci 4(1):1077

4. Fahad S, Bajwa AA, Nazir U et al (2017) Crop production under drought and heat stress: plant responses and management options. Front Plant Sci 8:1147. https://doi.org/10.3389/ fpls.2017.01147

5. Dias-Martins AM, Pessanha KLF, Pacheco S et al (2018) Potential use of pearl millet (Pennisetum glaucum (L.) R. Br.) in Brazil: food security, processing, health benefits and nutritional products. Food Res Int 109:175-186. https://doi.org/10.1016/j.foodr es.2018.04.023

6. Taylor AK, Lebwohl B, Snyder C et al (1993-2019) Celiac disease. In: Adam MP, Ardinger HH, Pagon RA et al (eds) Gene Reviews, University of Washington, Seattle (WA)

7. Fasano A, Catassi C (2001) Current approaches to diagnosis and treatment of celiac disease: an evolving spectrum. Gastroenterology 120(3):636-651. https://doi.org/10.1053/gast.2001.22123

8. Alaedini A, Green PHR (2005) Narrative review: Celiac disease: understanding a complex autoimmune disorder. Ann Intern Med 142(4):289-298 
9. Kim H-S, Patel KG, Orosz E et al (2016) Time trends in the prevalence of celiac disease and gluten-free diet in the US Population: results From the National Health and nutrition examination surveys 2009-2014. JAMA Intern Med 176(11):17161717. https://doi.org/10.1001/jamainternmed.2016.5254

10. Hallert C, Grant C, Grehn S et al (2002) Evidence of poor vitamin status in coeliac patients on a gluten-free diet for 10 years. Aliment Pharmacol Ther 16(7):1333-1339

11. Thompson T (2000) Folate, iron, and dietary fiber contents of the gluten-free diet. J Am Diet Assoc 100(11):1389-1396. https ://doi.org/10.1016/S0002-8223(00)00386-2

12. Udachan I, Sahoo AK (2017) Quality evaluation of gluten free protein rich broken rice pasta. Food Measure 11(3):1378-1385. https://doi.org/10.1007/s11694-017-9516-3

13. Melini V, Melini F (2019) Gluten-free diet: gaps and needs for a healthier diet. Nutrients 11:1. https://doi.org/10.3390/nu110 10170

14. van Hees NJM, Giltay EJ, Tielemans SMAJ et al (2015) Essential amino acids in the gluten-free diet and serum in relation to depression in patients with celiac disease. PLoS ONE 10(4):e0122619. https://doi.org/10.1371/journal.pone.0122619

15. Diez-Sampedro A, Olenick M, Maltseva T et al (2019) A glutenfree diet, not an appropriate choice without a medical diagnosis. J Nutr Metab 2019:2438934. https://doi.org/10.1155/2019/24389 34

16. Rondanelli M, Faliva MA, Gasparri C et al (2019) Micronutrients dietary supplementation advices for celiac patients on long-term gluten-free diet with good compliance: a review. Med (Kaunas) 55:7. https://doi.org/10.3390/medicina55070337

17. Meister A (1965) Biochemistry of the amino acids, 2nd edn. Elsevier Science, Burlington

18. Wu G (2009) Amino acids: metabolism, functions, and nutrition. Amino Acids 37(1):1-17. https://doi.org/10.1007/s0072 6-009-0269-0

19. Saleh ASM, Zhang Q, Chen J et al (2013) Millet grains: nutritional quality, processing, and potential health benefits. Comprehensive Rev Food Sci Food Safety 12(3):281-295. https://doi. org/10.1111/1541-4337.12012

20. AOAC International AOAC (1995) Official methods of analysis of AOAC international, 16th ed. Official method 925.10: solids (total) and moisture in flour: air oven method (925.10). AOAC international, Arlington, Virginia, USA

21. AOAC International AOAC (1995) Official methods of analysis of AOAC international, 16th ed. Official Method 994.12: Amino Acids in Feeds (994.12). AOAC international, Arlington, Virginia, USA

22. International Organization for Standardization (2016) Animal feeding stuffs: determination of amino acids content (ISO Standard No. 13903:2005)

23. Pasquali M, Longo N (2018) Newborn Screening and Inborn Errors of Metabolism. In: Rifai N, Horvath AR, Wittwer C (eds) Tietz textbook of clinical chemistry and molecular diagnostics. Elsevier, St. Louis, Missouri, pp 2045-2082

24. Crabb JW, West KA, Dodson WS et al (2001) Amino acid analysis. Curr Protoc Protein Sci Chapter 11:9. https://doi. org/10.1002/0471140864.ps1109s07
25. Wiedemair V, Mair D, Held C et al (2019) Investigations into the use of handheld near-infrared spectrometer and novel semiautomated data analysis for the determination of protein content in different cultivars of Panicum miliaceum L. Talanta 205:120115. https://doi.org/10.1016/j.talanta.2019.120115

26. Barkholt V, Jensen AL (1989) Amino acid analysis: determination of cysteine plus half-cystine in proteins after hydrochloric acid hydrolysis with a disulfide compound as additive. Anal Biochem 177(2):318-322. https://doi.org/10.1016/0003-2697(89)90059-6

27. Shen R, Ma Y, Jiang L et al (2018) Chemical composition, antioxidant, and antiproliferative activities of nine Chinese proso millet varieties. Food Agric Immunol 29(1):625-637. https://doi. org/10.1080/09540105.2018.1428283

28. Matuz J, Bartók T, Mórocz-Salamon K et al (2000) Structure and potential allergenic character of cereal proteins: I. Protein content and amino acid composition. Cereal Res Commun 28(3):263-270

29. Kalinova J, Moudry J (2006) Content and quality of protein in proso millet (Panicum miliaceum L.) varieties. Plant Foods Hum Nutr 61(1):45-49. https://doi.org/10.1007/s11130-006-0013-9

30. Souci SW, Kirchhoff E (2008) Food composition and nutrition tables: die zusammensetzung der lebensmittel, Nährwert-Tabellen, La composition des aliments, Tableaux des valeurs nutritives, 7., rev. und erg. Aufl. Medpharm Scientific Publ, Stuttgart

31. Awika JM (2011) Major cereal grains production and use around the world. Am Chem Soc 1089:1-13. https://doi.org/10.1021/ bk-2011-1089.ch001

32. Pedersen B, Knudsen KEB, Eggum BO (1989) Nutritive value of cereal products with emphasis on the effect of milling. World Rev Nutr Diet 60:1-91. https://doi.org/10.1159/000417519

33. USDA FoodData Central (2019) https://fdc.nal.usda.gov/. Accessed 11 May 2020

34. National Research Council, Commission on Life Sciences, Food and Nutrtion Board et al (eds) (1989) Recommended dietary allowances, 10th edn. National Academies Press, Washington

35. Joint Expert Consultation on Protein and Amino Acid Requirements in Human Nutrition; Weltgesundheitsorganisation; FAO; United Nations University; Joint WHO/FAO/UNU Expert Consultation on Protein and Amino Acid Requirements in Human Nutrition (2007) Protein and amino acid requirements in human nutrition: Report of a joint WHO/FAO/UNU Expert Consultation. WHO technical report series, vol 935. WHO, Geneva

36. Blank I, Robert F, Goldmann T et al (2005) Mechanisms of acrylamide formation: Maillard-induced transformation of asparagine. Adv Exp Med Biol 561:171-189. https://doi.org/10.1007/0-38724980-X_14

37. Rutherfurd SM, Gilani GS (2009) Amino acid analysis. Curr Protoc Protein Sci Chapter 11:9. https://doi.org/10.1002/0471140864 .ps1109s58

Publisher's Note Springer Nature remains neutral with regard to jurisdictional claims in published maps and institutional affiliations. 